\title{
Plant age and the inducibility of extrafloral nectaries in Vicia faba
}

\author{
Kevin E. Kwok • Robert A. Laird
}

Received: 19 June 2012/Accepted: 11 October 2012/Published online: 27 October 2012

(C) Springer Science+Business Media Dordrecht 2012

\begin{abstract}
Insect herbivory imposes a strong selection pressure on plants. As a result, plants have evolved a wide array of defences, including resistance traits that help them reduce the negative impact of herbivores. Along one axis of variation, these traits can be divided into direct resistance (physical and chemical defences) and indirect resistance (the recruitment of natural enemies of the herbivore via extrafloral nectar and other incentives). Along a second axis of variation, resistance can be split into constitutive resistance, which is always present, and induced resistance, which is expressed more strongly following damage to plant tissues. Interestingly, the strength and efficacy of all of constitutive-direct, constitutive-indirect, induceddirect, and induced-indirect resistance can vary with plant age and ontological stage. Here, we examine the effect of plant age on an induced-indirect resistance trait, the deployment of extrafloral nectaries (EFNs) to attract pugnacious ants, in a short-lived annual, broad bean (Vicia faba L.). We demonstrate that in severely damaged plants, the induction of EFNs is greater in older plants (5-6 weeks) than in younger plants (2-4 weeks); however, in more moderately damaged plants, the induction of EFNs is unaffected by plant
\end{abstract}

K. E. Kwok · R. A. Laird $(\bowtie)$

Department of Biological Sciences, University of Lethbridge, Lethbridge, AB T1K 3M4, Canada e-mail: robert.laird@uleth.ca

K. E. Kwok

e-mail: k.kwok@uleth.ca age. This suggests the hypothesis that a plant's ability to induce extrafloral nectar, and therefore recruit more ant "bodyguards," may be related to the interaction of plant age and severity of damage.

Keywords Plant-herbivore interactions - Insect damage $\cdot$ Indirect defence $\cdot$ Plant senescence

\section{Introduction}

Herbivory is one of the most common and important interspecific interactions in nature (Strauss and Zangerl 2002). The loss of tissue to herbivores can be very costly to plants and can lead to decreased reproductive potential or even death (Belsky 1986); as a result, plants have evolved an array of defences that arise from a variety of underlying mechanisms (Walling 2000). Broadly, defences can be divided into the categories of tolerance and resistance (Núñez-Farfán et al. 2007). Tolerance refers to the strategy of reducing plant fitness-loss without reducing the degree of herbivore interaction with the plant (Strauss and Agrawal 1999; Juenger and Lennartsson 2000); for example, plants may increase leaf-tissue production to mitigate the loss of tissues to herbivores. Resistance refers to the strategy of reducing plant fitness-loss by reducing the herbivore's interaction with the plant (Rausher 2001); this second type of defence is the focus of this study.

Resistance can be further subdivided into direct and indirect resistance (Heil 2008, 2010). Direct resistance 
can take the form of physical resistance (e.g., thorns and trichomes; Gowda 1997) and chemical resistance (e.g., Ayres et al. 1997). Indirect resistance relies on extrafloral nectar (Koptur 1989, 1992), volatile organic compounds (Pare and Tumlinson 1999), Beltian bodies (Heil et al. 2004a), and other incentives to attract pugnacious insect "bodyguards" (e.g., parasitoids, aggressive ants), which attack herbivores and discourage them from consuming plant tissue (Bentley 1977; Beattie 1985; Beattie and Hughes 2002). Both direct and indirect resistance may be costly (Gulmon and Mooney 1986; Bergelson and Purrington 1996; Rausher 2001; Strauss et al. 2002; Heil 2010), so as a cost-saving measure, they are often induced by damage to plant tissue rather than expressed constitutively (Karban and Myers 1989; Karban and Baldwin 1997; Agrawal 1998; Agrawal and Rutter 1998; Arimura et al. 2005). Many of these damage-induction systems create a systemic response throughout the entire plant in order to prevent future damage (e.g., Wäckers and Bezemer 2003; Schilmiller and Howe 2005).

The intensity of direct and indirect resistance often changes with plant age/ontogeny as does tolerance (e.g., Boege et al. 2007; Hódor et al. 2008; Tucker and Avila-Sakar 2010; Akiyama and Ågren 2012). Both positive and negative relationships between resistance and age have been reported, with the direction of the relationship thought to represent the outcome of the net selective effects of the importance of herbivory at difference life stages and the cost of deploying resistance (or an alternative strategy such as tolerance) (Boege and Marquis 2005; Boege et al. 2007). For example, in terms of constitutive-direct resistance, Quintero and Bowers $(2011,2012)$ demonstrated that mature Plantago lanceolata plants had greater concentrations of iridoid glycosides than juvenile plants. On the other hand, taking a within-plant perspective, Axelsson et al. (2011) showed that higher (younger) leaves had greater concentrations of 24 of 25 chemical substances compared to lower (older) leaves, and that these differences translated into an increased preference of slugs for older leaves. In addition to these examples, there are many other instances of positive (e.g., Elger et al. 2009; Broekgaarden et al. 2012), negative (e.g., Boege et al. 2007), neutral (e.g., Boege 2005; da Costa et al. 2011), and non-monotonic (e.g., Oldham et al. 2011) resistance-age relationships involving constitutive-direct defences (see recent reviews by Boege and Marquis 2005; Boege et al. 2007, 2011; Hanley et al. 2007; Barton and Koricheva 2010). In terms of constitutive-indirect resistance, Radhika et al. (2008) conducted a within-plant study on Phaseolus lunatus and Ricinus communis and showed that younger leaves produced ant-attracting extrafloral nectar at a greater rate than older leaves. Similarly, Heil et al. (2004b) showed that ants preferentially defend young leaves in the tropical ant-plant Macaranga bancana (also see Heil et al. 2000).

Far fewer studies have considered the relationship between induced resistance and plant age, in terms of both direct and indirect resistance (Boege and Marquis 2005); however, a number of recent studies have attempted to rectify this, at least in terms of the direct resistance. In addition to their work on constitutive defences, Quintero and Bowers (2011) also investigated the effect of plant age on the inducibility of iridoid glycosides in P. lanceolata. They found that inducible defences (in terms of the proportion of iridoid glycoside production composed of catalpol following damage by Junonia coenia caterpillars) were present in juvenile plants, but not in mature plants. In another example, Shiojiri et al. (2011) studied sagebrush (Artemisia tridentata) and found that induced resistance mediated by volatile organic compounds was much stronger in young plants compared to old plants. In contrast, Santos and Fernandes (2010) discovered a positive relationship between plant age and the induced anti-gall "hypersensitive response" in cashew plants, Anacardium occidentale.

The effect of plant age on inducible indirect resistance is perhaps the least well understood of the four constitutive/inducible-by-direct/indirect combinations; however, researchers are beginning to address this. For instance, Rostás and Eggert (2008) found that herbivore-induced volatiles, used to recruit herbivores' natural enemies, were emitted in greater amounts per biomass in younger plants and younger leaves of Glycine max when subjected to Spodoptera frugiperda herbivory. In addition, Hare (2010) studied the perennial plant Datura wrightii and found that volatiles were inducible in the spring, but not in the fall; moreover, the chemical composition of herbivore-induced plant volatiles changed over the growing season. In another study, Romero and Izzo (2004) investigated the tropical ant-plant Hirtella myrmecophila which rewards ant bodyguards with domatia but not food rewards. They found that within individual 
plants, ant recruitment following artificial damage was stronger in young leaves compared to mature leaves. Another important type of indirect defence involves ants that are attracted not by domatia but by food rewards presented as extrafloral nectaries (EFNs). Yet, despite the fact that many species across many families have EFNs (e.g., Ellias 1983; Koptur 1992), and they are often inducible (e.g., Koptur 1989; Mondor and Addicott 2003; Ness 2003; Mondor et al. 2006), the effect of plant age on the inducibility of this indirect defence has received little attention. Nevertheless, Radhika et al. (2008), in addition to showing that Phaseolus lunatus and Ricinus communis had greater constitutive production of extrafloral nectar in young compared to old leaves, also showed that young leaves had greater induction of extrafloral nectar (within individuals in both cases).

The goal of our research was to determine how variation in age among plants (rather than among organs within individuals as in Radhika et al. 2008) shapes plants' abilities to respond to damage by inducing the increased production of EFNs. Based on previous research on indirect inducible defences (cited above), we predicted that younger plants would have greater EFN induction than older plants. We tested this prediction in a sequence of three experiments involving broad bean, Vicia faba, a plant that produces inducible, ant-attracting EFNs. Because the second and third experiments in this sequence each built directly on the results of experiments that preceded them, we present the methods and results of each experiment in series rather than in parallel.

\section{Materials and methods common to all experiments}

Study species

Broad bean, Vicia faba L. (cv. "Broad Windsor," Fabaceae) is a short-lived annual legume with compound leaves (2-6 leaflets per leaf) and white-andpurple flowers (Duke 1981). It produces conspicuous purple EFNs on its stipules, which grow in pairs at the base of leaf petioles (Mondor and Addicott 2003). Typically, an individual pair of stipules has zero, one, or two EFNs, although more than two are sometimes possible (Laird and Addicott 2007). The EFNs act as a reward, attracting mutualistic ants (Bugg and Ellis 1990; Engel et al. 2001). In exchange for nectar, the ants protect their host plant from herbivores (Katayama and Suzuki 2004). The EFNs of $V$. faba are inducible under certain environmental conditions; damaged plants produce more EFNs compared to undamaged plants, at least when soil nutrients are abundant, but not necessarily when soil nutrients are more scarce (Mondor and Addicott 2003; Mondor et al. 2006; Laird and Addicott 2007).

Planting procedure

All plants were grown in one trade-gallon pots $(16.5 \mathrm{~cm}$ diameter $\times 17.8 \mathrm{~cm}$ high; $2.78 \mathrm{~L}$ ). Prior to planting, each plot was filled with Sunshine Mix \#1 planting medium (Sun Gro Horticulture, Vancouver, Canada), leaving $5 \mathrm{~cm}$ of space at the top of each pot. Scotts Osmocote 14-14-14 NPK controlled-release fertilizer $(20.0 \mathrm{~g})$ was spread along the surface of the planting medium and an additional $2 \mathrm{~cm}$ of planting medium was added to the pot. (Mondor et al. 2006 found that EFN induction is enhanced in our study species under highnutrient conditions.) A single $V$. faba seed was planted $3 \mathrm{~cm}$ deep in the center of each pot. The pots were placed in a greenhouse with natural photoperiod and watered until saturation every 4 days. After 2 weeks of plant growth, all plants were loosely tied to $91 \mathrm{~cm}$ bamboo stakes to promote an upright growth form.

\section{Experiment I: age-dependent severe leaf damage and the induction of EFNs}

Experiment I: methods

The purpose of Experiment I was to determine whether the inducibility of EFNs in $V$. faba was age dependent. The experiment consisted of two DAMAGE treatments (damaged and control) crossed with five AGE treatments that varied in the time when the DAMAGE treatments were applied $(2,3,4,5$, and 6 weeks after planting the seed). In the DAMAGE treatments, damaged plants had the distal third of each leaf excised with scissors; mechanical damage has been shown to be sufficient to induce EFNs in V. faba (Mondor and Addicott 2003; Mondor et al. 2006). Control plants were left undamaged. The lower end of the AGE treatments was chosen to reflect findings of earlier research (i.e., Mondor and Addicott 2003 reported damage induction of EFNs in 18-day-old plants); the upper end was chosen to reflect 
the short lifespan of $V$. faba (plants entered the flowering stage in the sixth week post-planting).

Each DAMAGE $\times$ AGE combination was replicated seven times in each of five spatio-temporal randomized blocks (i.e., BLOCK treatment). Thus, Experiment I consisted of 350 plants in a full-factorial design. The blocks were planted in a staggered-start pattern, one block every 8 days (starting May 3, 2010), to reduce the potential for AGE to be confounded by variation with weather and photoperiod associated with changes in the calendar date.

Once the date associated with a particular AGE treatment arrived, we recorded the number of stipule pairs with different numbers of EFNs on them $(0,1$, or 2). The appropriate DAMAGE treatment was then applied to each plant. The EFNs were re-measured 1 week later, with the total number of EFNs produced in that week used to detect differences between the various treatments.

The data from Experiment I were analyzed using a linear model including BLOCK, AGE, and DAMAGE and their two- and three-way interactions. Several plants died before the end of the experiment and were excluded from the analyses. Because EFNs are present in $V$. faba only on the stipules, we included number of new nodes (i.e., NODE treatment) as a covariate to account for variation in plant growth, which was present among individual plants even within blocks. We note, however, that when NODE was used as the dependent variable, rather than as a covariate, there were no significant effects of DAMAGE or the DAMAGE by AGE interaction in this experiment or the two succeeding experiments. We subsequently used planned orthogonal contrasts to test for differences between control and damaged plants at each level of AGE. Analyses were conducted in JMP 7.0.2 (SAS Institute, 2007).

\section{Experiment I: results}

There was a significant effect of AGE on the number of EFNs produced in the week following the application of the DAMAGE treatment; specifically, older plants produced more EFNs per week compared to young plants (Fig. 1; Table 1). In addition, there was a significant effect of DAMAGE on weekly EFN production with damaged plants producing more than control plants (Fig. 1; Table 1). Thus, our results supported previous studies which showed that EFNs are

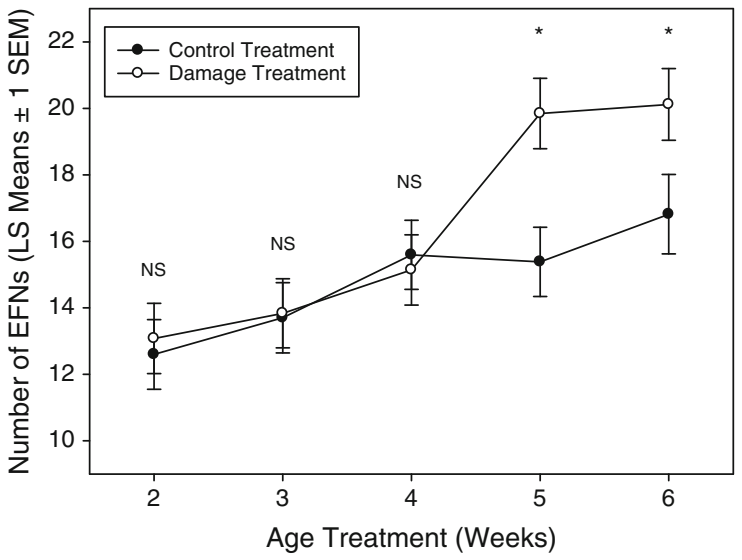

Fig. 1 Number of EFNs produced in the week following the application of the DAMAGE treatments at various levels of AGE (i.e., 2-6 weeks since planting) in Experiment I. Symbols show least-squared means \pm 1 SEM, after accounting for the factor BLOCK and the covariate NODES (i.e., number of nodes produced in the week following the application of the DAMAGE treatments). Black symbols indicate the control treatment; white symbols indicate the damage treatment. NS refers to a non-significant planned contrast between control and damage plants for a particular AGE treatment $(P>0.05)$; '*' refers to a significant planned contrast $(P<0.05)$. Statistical analyses associated with these data are given in Table 1

inducible in $V$. faba (Mondor and Addicott 2003; Mondor et al. 2006). Most pertinently, there was a marginally significant DAMAGE $\times$ AGE interaction $(P=0.08)$, suggesting that the inducibility of EFNs may be age dependent (Table 1). In particular, planned comparisons showed that EFNs were only induced in the oldest plants, i.e., those that were damaged at age 5 or 6 weeks (Fig. 1).

\section{Experiment II: age-dependent moderate leaf damage and the induction of EFNs}

Experiment II: methods

The results of Experiment I were counter to our original prediction and somewhat surprising given that previous researchers have used similar experimental conditions to demonstrate EFN induction in $V$. faba plants that were approximately the same age as our younger plants in which no induction occurred (Fig. 1). For example, Mondor and Addicott (2003) found that significantly more EFNs were produced in 1 week in 18-day-old plants that were subjected to having the distal third of one leaf (or both leaves) of a 
Table 1 Experiment I results (linear model) for the interactive effects of BLOCK, AGE, and DAMAGE, plus the covariate NODES, on the number of EFNs produced in 1 week following the application of the DAMAGE treatments

Figure 1 shows the data associated with this table $* P<0.05$

\begin{tabular}{lrrrrc}
\hline Source & df & \multicolumn{1}{c}{ SS } & \multicolumn{1}{c}{ MS } & \multicolumn{1}{c}{ P } \\
\hline NODES (covariate)* & 1 & 9422.93 & 9422.93 & 257.85 & $<0.0001$ \\
BLOCK & 4 & 218.19 & 54.55 & 1.49 & 0.205 \\
AGE* & 4 & 1361.37 & 340.34 & 9.31 & $<0.0001$ \\
DAMAGE* & 1 & 203.47 & 203.47 & 5.57 & 0.0190 \\
BLOCK $\times$ AGE & 16 & 702.16 & 43.88 & 1.20 & 0.266 \\
BLOCK $\times$ DAMAGE & 4 & 117.25 & 29.31 & 0.802 & 0.525 \\
AGE $\times$ DAMAGE & 4 & 304.87 & 76.22 & 2.09 & 0.0828 \\
BLOCK $\times$ AGE $\times$ DAMAGE & 16 & 618.47 & 38.65 & 1.06 & 0.396 \\
ERROR & 282 & 10305.46 & 36.54 & & \\
\hline
\end{tabular}

leaf-pair excised, compared to undamaged controls. Similarly, Mondor et al. (2006) excised the distal third of one leaf in the topmost leaf pair and demonstrated EFN induction, relative to undamaged controls, in $\sim 10 \mathrm{~cm}$ plants in the $2-3$ leaf-stage (i.e., very young plants), at least when plants were supplemented with nutrients (also see discussion in Laird and Addicott 2007). The most conspicuous difference between these previous papers and our Experiment $\mathrm{I}$ is that our plants were subjected to considerably more damage: in our experiment, every leaf in the damage treatment had its distal third removed. Therefore, we surmised that this level of damage may have been sufficiently great that in young plants, any potential EFN induction was offset by the loss of photosynthetic tissues available to pay for the cost of construction of new EFNs. To this end, Experiment II, which began January 17, 2011, consisted of the same procedure detailed in Experiment I with one exception: instead of damaging all leaves in the damage treatment, only one leaf from each leaf pair was damaged. (A pilot study, not shown, suggested that this was an appropriate level of damage to observe EFN induction in young plants.) Analyses were the same as in Experiment I.

\section{Experiment II: results}

There was a significant effect of AGE on the number of EFNs produced in the week following the application of the DAMAGE treatment; as in Experiment I, older plants in Experiment II produced more EFNs per week compared to young plants (Fig. 2; Table 2). Likewise, there was a significant effect of DAMAGE on weekly EFN production with damaged plants producing more than control plants (Fig. 2; Table 2). This effect was seen across all five AGE treatments in aggregate
(Table 2); however, planned contrasts did not detect any significant differences between control and damaged plants at any one level of AGE (Fig. 2). Further, in contrast to Experiment I, in Experiment II there was not even a marginally significant DAMAGE $\times$ AGE interaction, indicating that at this more moderate level of damage, there was no evidence of age dependence in the induction of EFNs (Fig. 2, Table 2).

\section{Experiment III: interactive effects of severity of leaf damage and age on the induction of EFNs}

Experiment III: methods

Taken together, Experiments I and II suggest that there are complex age- and damage-severity-dependent changes in the induction of EFNs in Vicia faba. Specifically, we demonstrated that induction increases more with age in severely damaged than in moderately damaged plants (Figs. 1, 2). However, Experiments I and II were two separate experiments; the goal of Experiment III was to combine the interactive effects of damage severity and age within a single experiment.

In contrast to Experiments I and II, Experiment III used only two levels of the AGE treatment specifying the time that the DAMAGE treatments were applied: 2 and 6 weeks after seeding. There were three DAMAGE treatments: moderate damage (i.e., the distal third of one leaf in every leaf pair was excised, as in Experiment II), severe damage (i.e., the distal third of all leaves was excised, as in Experiment I), as well as undamaged controls. As with Experiments I and II, Experiment III had five spatio-temporal blocks (i.e., BLOCK treatment), arranged in a staggered-start fashion. Each block consisted of seven individuals of each 


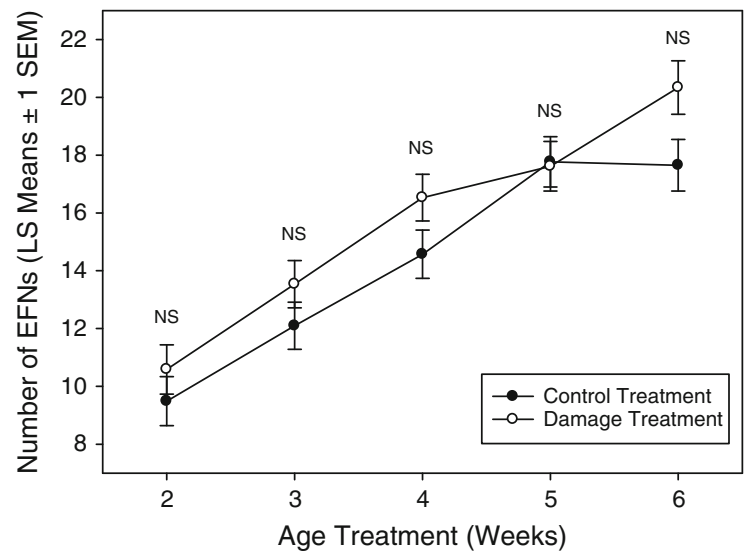

Fig. 2 Number of EFNs produced in the week following the application of the DAMAGE treatments at various levels of AGE (i.e., 2-6 weeks since planting) in Experiment II. Symbols show least-squared means $\pm 1 \mathrm{SEM}$, after accounting for the factor BLOCK and the covariate NODES (i.e., number of nodes produced in the week following the application of the DAMAGE treatments). Black symbols indicate the control treatment; white symbols indicate the damage treatment. NS refers to a non-significant planned contrast between control and damage plants for a particular AGE treatment (all $P>0.05$, despite the fact that DAMAGE had a significant effect in aggregate). Statistical analyses associated with these data are given in Table 2 for $\log (x+1)$ transformed data, to correct for heteroscedasticity; data are shown here untransformed for ease of understanding

combination of the AGE and DAMAGE treatments for a total of 210 plants. The first block was planted on September 12, 2011. Each subsequent block was planted 8 days after the previous block as in Experiments I and II. Analyses were the same as in Experiments I and II, except that non-orthogonal planned contrasts were used to compare each of the three DAMAGE treatment pairs within each level of AGE. To account for non-orthogonality, we used a corrected (i.e., decreased) $\alpha$-value associated with the contrasts, according to the Dunn-Šidák procedure.

Experiment III: results

As in Experiments I and II, there was a strong effect of AGE on the number of EFNs produced in the week following the application of the damage treatments in Experiment III (Table 3); once again, older plants produced more EFNs compared to younger plants (Fig. 3). However, unlike the first two experiments, in Experiment III, there was no difference between damaged and control plants: plants in all levels of damage produced approximately the same number of EFNs (Fig. 3; Table 3).

\section{Discussion}

Optimal defence theory predicts that plants should allocate their resources to resistance in such a way as to maximize the difference between the fitness benefits of resistance (e.g., reduced tissue-loss to herbivores) and the fitness costs of resistance (e.g., lost opportunity cost associated with allocating fewer resources to growth and reproduction) (Boege and Marquis 2005). Because both costs and benefits are liable to change with plant age and stage, the level of expression of plant defences is predicted to be age dependent-a prediction that is now supported by a growing number of empirical studies investigating a wide range of plant species and defence types (e.g., Boege et al. 2007; Elger et al. 2009; Oldham et al. 2011; Broekgaarden et al. 2012). Of the four main categories of resistance types-constitutive-direct resistance, constitutive-
Table 2 Experiment II results (linear model) for the interactive effects of BLOCK, AGE, and DAMAGE, plus the covariate NODES, on the number of EFNs produced in one week following the application of the DAMAGE treatments $(\log (x+1)$ transformed due to heteroscedasticity)

Figure 2 shows the data associated with this table * $P<0.05$

\begin{tabular}{lrllcc}
\hline Source & df & SS & MS & $F$ & $P$ \\
\hline NODES (covariate)* & 1 & 2.39 & 2.39 & 79.72 & $<0.0001$ \\
BLOCK & 4 & 0.120 & 0.0299 & 0.996 & 0.410 \\
AGE* & 4 & 4.16 & 1.04 & 34.69 & $<0.0001$ \\
DAMAGE* & 1 & 0.147 & 0.147 & 4.90 & 0.0276 \\
BLOCK $\times$ AGE & 16 & 0.414 & 0.0259 & 0.863 & 0.612 \\
BLOCK $\times$ DAMAGE* & 4 & 0.563 & 0.141 & 4.69 & 0.00111 \\
AGE $\times$ DAMAGE & 4 & 0.0832 & 0.0208 & 0.694 & 0.597 \\
BLOCK $\times$ AGE $\times$ & 16 & 0.510 & 0.0319 & 1.06 & 0.391 \\
DAMAGE & & & & & \\
ERROR & 283 & 8.49 & 0.0300 & & \\
\hline
\end{tabular}


indirect resistance, induced-direct resistance, and induced-indirect resistance-the last of these has received the least attention, even though indirect defences are very common across many plant families (e.g., Koptur 1989), and inducible defences are, by their nature as cost-saving mechanisms, thought to be strongly molded by economic cost-benefit considerations (Karban and Myers 1989). To this end, we conducted experiments to investigate whether an induced-indirect defence, namely the production of EFNs to attract ant bodyguards, is age and damage severity dependent.

Our results suggest that this inducible indirect defence may be related to age and damage severity in an interactive fashion in broad bean, Vicia faba. Our most striking and consistent finding was related to the main effect of plant age. In all three of our experiments, there was a strong effect of age with older plants producing more EFNs compared to younger plants (Figs. 1, 2, 3), even after accounting for differences in plant size (i.e., number of new nodes). This increase in a resistance trait with age matches several other researchers' findings from a diverse suite of species and contexts (e.g., Elger et al. 2009; Quintero and Bowers 2011, 2012; Broekgaarden et al. 2012). Thus, our study adds to the growing body of work suggesting that plant age is a strong determinant of traits that confer resistance to herbivory (Boege and Marquis 2005).

Our main focus, however, was not on the effect of age alone, but rather on the interactive effects of age and damage; i.e., whether the inducibility of EFNs was affected by plant age. Experiments I and II showed that the effect of age on EFN inducibility further depends on the severity of damage incurred by the plant (Figs. 1, 2). Specifically, when damage was severe, as in Experiment I, only older plants exhibited

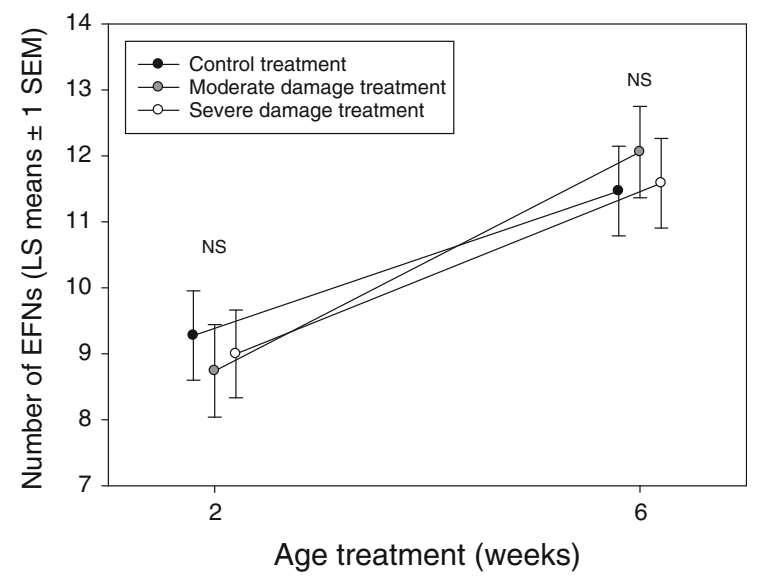

Fig. 3 Number of EFNs produced in the week following the application of the damage treatments at of the DAMAGE treatments at the two levels of AGE (i.e., 2 and 6 weeks since planting) in Experiment III. Symbols show least-squared means \pm 1 SEM, after accounting for the factor BLOCK and the covariate NODES (i.e., number of nodes produced in the week following the application of the DAMAGE treatments). Black symbols indicate the control treatment; gray symbols indicate the moderate damage treatment; white symbols indicate the severe damage treatment. $N S$ refers to non-significant planned contrasts among all pairs of control, and moderate and severely damaged plants, for particular AGE treatments. Statistical analyses associated with these data are given in Table 3

inducibility; in younger plants, there was no difference between the number of EFNs produced following damage versus no damage (Fig. 1). Thus, at this level of damage, the direction of the relationship with age of this inducible resistance trait followed the same trend as direction of the relationship with age of its constitutive counterpart: inducibility increased with age. On the other hand, when damage was more moderate, inducibility remained relatively constant with plant age (Fig. 2). Taken together, along with the strong age-dependence of the constitutive production
Table 3 Experiment III results (linear model) for the interactive effects of BLOCK, AGE, and DAMAGE, plus the covariate NODES, on the number of EFNs produced in 1 week following the application of the DAMAGE treatments

Figure 3 shows the data associated with this table * $P<0.05$

\begin{tabular}{lrcccr}
\hline Source & df & \multicolumn{1}{c}{ SS } & MS & \multicolumn{2}{c}{ P } \\
\hline NODES (covariate)* & 1 & 1496.00 & 1496.00 & 109.36 & $<0.0001$ \\
BLOCK $^{*}$ & 4 & 139.85 & 34.96 & 2.56 & 0.0408 \\
AGE* & 1 & 222.18 & 222.18 & 16.24 & $<0.0001$ \\
DAMAGE & 2 & 0.408 & 0.204 & 0.0149 & 0.985 \\
BLOCK $\times$ AGE* & 4 & 160.71 & 40.18 & 2.94 & 0.022 \\
BLOCK $\times$ DAMAGE & 8 & 164.79 & 20.60 & 1.51 & 0.159 \\
AGE $\times$ DAMAGE & 2 & 10.33 & 5.16 & 0.378 & 0.686 \\
BLOCK $\times$ AGE $\times$ DAMAGE & 8 & 92.62 & 11.58 & 0.846 & 0.563 \\
ERROR & 165 & 2257.06 & 13.68 & & \\
\hline
\end{tabular}


of EFNs, these results on EFN induction suggest that EFNs may be relatively more costly for younger $V$. faba plants than for older plants. That is, when damage is only moderate, young plants are able to increase their EFN production to the same degree as older plants; however, when damage is more severe, the increased loss of photosynthetic tissue may prevent young, resource-limited plants from having sufficient resources to devote to the increased construction of EFNs. Understanding and testing the physiological mechanisms underlying this resource-limitation hypothesis represent an important avenue for future research.

Experiment III was designed to combine relevant features of Experiments I and II in order to directly test for the interactive effects of damage severity and plant age on EFN induction. Although the plants were of the same species and same seed source, and the experimental methods are largely identical, Experiment III failed to detect any induction of EFNs in either relatively young or old plants (Fig. 3), making it difficult to further evaluate our interpretation arising from Experiments I and II. The main difference with Experiment III compared to Experiments I and II was the time of year it took place: Experiment III took place in the autumn, while Experiments I and II took place in the summer and winter, respectively. We speculate that the staggered-start spatio-temporal randomized block design may have been insufficient to account for the relatively fast change in photoperiod during the autumn (compared to the relatively slow change in photoperiod during the winter and summer). Because extrafloral nectar production requires carbohydrates from photosynthesis, if date- and plant agedependent changes in light availability are confounded, the effects of plant age on EFN induction may be obscured. We emphasize, however, that we do not know for certain what led to the lack of EFN induction in Experiment III. But in any case, taken together, our suite of experiments suggests that EFN induction may be strongly mediated by environmental context, as noted by other $V$. faba researchers (e.g., Mondor and Addicott 2003; Mondor et al. 2006; also see Laird and Addicott 2007).

Our research contributes to the wider goal of understanding how plant age shapes anti-herbivore resistance traits. An emerging synthesis will require that all types of plant resistance along both the constitutive-induced and direct-indirect axes of variation be investigated. Furthermore, future studies should move beyond the pattern-description stage and delve deeper into the physiological mechanisms underlying resistance costs and benefits, in order to gain better insight into how well patterns of agedependent resistance can be explained by optimal defence theory.

Acknowledgments We thank Patrick Barks, Vincent Hervet, R. J. Murphy, three anonymous reviewers, and the associate editor for their valuable comments on the manuscript. Funding for this project was provided by a University of Lethbridge Research Start-up Grant (RL), a Natural Sciences and Engineering Research Council (Canada) Discovery Grant (RL), and a University of Lethbridge Luke Stebbins Symposium award (KK).

\section{References}

Agrawal AA (1998) Induced responses to herbivory and increased plant performance. Science 279:1201-1202

Agrawal AA, Rutter MT (1998) Dynamic anti-herbivore defense in ant-plants: the role of induced responses. Oikos 83:227-236

Akiyama R, Ågren J (2012) Magnitude and timing of leaf damage affect seed production in a natural population of Arabidopsis thaliana (Brassicaceae). PLoS ONE 7:e30015

Arimura G, Kost C, Boland W (2005) Herbivore-induced, indirect plant defences. Biochim Biophys Acta 1734:91-111

Axelsson EP, Hjältén J, Whitham TG, Julkenen-Tiitto R, Pilate G, Wennström A (2011) Leaf ontogeny interacts with Bt modification to affect innate resistance in GM aspens. Chemoecology 21:161-169

Ayres MP, Clausen TP, MacLean SF Jr, Redman AM, Reichardt PB (1997) Diversity of structure and antiherbivore activity in condensed tannins. Ecology 78:1696-1712

Barton KE, Koricheva J (2010) The ontogeny of plant defense and herbivory: characterizing general patterns using metaanalysis. Am Nat 175:481-493

Beattie AJ (1985) The evolutionary ecology of ant-plant mutualisms. Cambridge University Press, Cambridge

Beattie AJ, Hughes L (2002) Ant-plant interactions. In: Herrera CM, Pellmyr O (eds) Plant-animal interactions. Blackwell Sciences, Oxford

Belsky AJ (1986) Does herbivory benefit plants? A review of the evidence. Am Nat 127:870-892

Bentley BL (1977) Extrafloral nectaries and protection by pugnacious bodyguards. Ann Rev Ecol Syst 8:407-427

Bergelson J, Purrington CB (1996) Surveying patterns of in the costs of resistance in plants. Am Nat 148:536-558

Boege K (2005) Influence of plant ontogeny on compensation to leaf damage. Am J Bot 92:1632-1640

Boege K, Marquis RJ (2005) Facing herbivory as you grow up: the ontogeny of resistance in plants. Trends Ecol Evol 20:441-448

Boege K, Dirzo R, Siemens D, Brown P (2007) Ontogenic switches from plant resistance to tolerance: minimizing costs with age? Ecol Lett 10:177-187 
Boege K, Barton KE, Dirzo R (2011) Influence of tree ontogeny on plant-herbivore interactions. In: Meinzer FC, Lachenbruch B, Dawson TE (eds) Size and age-related changes in tree structure and function, tree physiology, vol 4. Springer, New York

Broekgaarden C, Riviere P, Steenhuis G, del sol Cuenca M, Kos M, Vosman B (2012) Phloem-specific resistance in Brassica oleracea against the whitefly Aleyrodes proletella. Entomol Exp Appl 142:153-164

Bugg RL, Ellis RT (1990) Insects associated with cover crops in Massachusetts. Biol Agric Hortic 7:47-68

da Costa FV, de Siqueira Neves F, de Oliveira Silva J, Faugundes M (2011) Relationship between plant development, tannin concentration and insects associated with Copaifera langsdorffii (Fabaceae). Arthropod-Plant Interact 5:9-18

Duke JA (1981) Handbook of legumes of world economic importance. Plenum Press, New York

Elger A, Lemoine DG, Fenner M, Hanley ME (2009) Plant ontogeny and chemical defence: older seedlings are better defended. Oikos 118:767-773

Ellias TS (1983) Extrafloral nectaries: their structure and distribution. In: Bently BL, Elias TS (eds) The biology of nectaries. Columbia University Press, New York

Engel V, Fischer MK, Wäckers FL, Völkl W (2001) Interactions between extrafloral nectaries, aphids and ants: are there competition effects between plant and homopteran sugar sources? Oecologia 129:577-584

Gowda JH (1997) Physical and chemical response of juvenile Acacia tortilis trees to browsing: experimental evidence. Funct Ecol 11:106-111

Gulmon SL, Mooney HA (1986) Costs of defence and their effects on plant productivity. In: Givnish TJ (ed) On the economy of plant form and function. Cambridge University Press, Cambridge

Hanley ME, Lamont BB, Fairbanks MM, Rafferty CM (2007) Plant structural traits and their role in anti-herbivore defence. Perspect Plant Ecol Evol Syst 8:157-178

Hare JD (2010) Ontogeny and season constrain the production of herbivore-inducible plant volatiles in the field. J Chem Ecol 36:1363-1374

Heil M (2008) Indirect defence via tritrophic interactions. New Phytol 178:41-61

Heil M (2010) Plastic defence expression in plants. Evol Ecol 24:555-569

Heil M, Fiala B, Baumann B, Linsenmair KE (2000) Temporal, spatial and biotic variations in extrafloral nectar secretion by Macaranga tanarius. Funct Ecol 14:749-757

Heil M, Baumann B, Kruger R, Linsenmair KE (2004a) Main nutrient compounds in food bodies of Mexican Acacia antplants. Cheomoecology 14:45-52

Heil M, Feil D, Hilpert A, Linsenmair KE (2004b) Spatiotemporal patterns in indirect defence of a South-East Asian antplant support the optimal defence hypothesis. J Trop Ecol 20:573-580

Hódor JA, Zamora R, Castro J, Gómez JM, García D (2008) Biomass allocation and growth responses of Scots pine saplings to simulated herbivory depend on plant age and light availability. Plant Ecol 197:229-238

Juenger T, Lennartsson T (2000) Tolerance in plant ecology and evolution: toward a more unified theory of plant-herbivore interaction. Evol Ecol 14:283-287
Karban R, Baldwin IT (1997) Induced responses to herbivory. University of Chicago Press, Chicago

Karban R, Myers JH (1989) Induced plant responses to herbivory. Annu Rev Ecol Syst 20:331-348

Katayama N, Suzuki N (2004) Role of extrafloral nectaries of Vicia faba in attraction of ants and herbivore exclusion by ants. Entomol Sci 7:119-124

Koptur S (1989) Is extrafloral nectar production an inducible defense? In: Bock JH, Linhart YB (eds) The evolutionary ecology of plants. Westview Press, Boulder

Koptur S (1992) Interactions between insects and plants mediated by extrafloral nectaries. In: Bernays E (ed) Insect plant interactions. CRC Press, Boca Raton

Laird RA, Addicott JF (2007) Arbuscular mycorrhizal fungi reduce the construction of extrafloral nectaries in Vicia faba. Oecologia 152:541-551

Mondor EB, Addicott JF (2003) Conspicuous extra-floral nectaries are inducible in Vicia faba. Ecol Lett 6:495-497

Mondor EB, Tremblay MN, Messing RH (2006) Extrafloral nectary phenotypic plasticity is damage- and resourcedependent in Vicia faba. Biol Lett 2:583-585

Ness JH (2003) Catalpa bignonioides alters extrafloral nectar production after herbivory and attracts ant bodyguards. Oecologia 134:210-218

Núñez-Farfán J, Fornoni J, Valverde PL (2007) The evolution of resistance and tolerance to herbivores. Annu Rev Ecol Evol Syst 38:541-566

Oldham M, Ransom CV, Ralphs MH, Gardner DR (2011) Galegine content in goatsrue (Galega officinalis) varies by plant part and phenological growth stage. Weed Sci 59:349-352

Pare PW, Tumlinson JH (1999) Plant volatiles as a defense against insect herbivores. Plant Physiol 121:325-332

Quintero C, Bowers MD (2011) Plant induced defences depend more on plant age than previous history of damage: implications for plant-herbivore interactions. J Chem Ecol 37:992-1001

Quintero C, Bowers MD (2012) Changes in plant chemical defenses and nutritional quality as a function of ontogeny in Plantago lanceolata (Plantaginaceae). Oecologia 168:471-481

Radhika V, Kost C, Bartram S, Heil M, Boland W (2008) Testing the optimal defence hypothesis for two indirect defences: extrafloral nectar and volatile organic compounds. Planta 228:449-457

Rausher MD (2001) Co-evolution and plant resistance to natural enemies. Nature 411:857-864

Romero GQ, Izzo TJ (2004) Leaf damage induces ant recruitment in the Amazonian ant-plant Hirtella myrmecophila. J Trop Ecol 20:675-682

Rostás M, Eggert K (2008) Ontogenetic and spatio-temporal patterns of induced volatiles in Glycine max in the light of the optimal defence hypothesis. Chemoecology 18:29-38

Santos JC, Fernandes GW (2010) Mediation of herbivore attack and induced resistance by plant vigor and ontogeny. Acta Oecol 36:617-625

Schilmiller AL, Howe GA (2005) Systemic signalling in the wound response. Curr Opin Plant Biol 8:369-377

Shiojiri K, Karban R, Ishizaki S (2011) Plant age, seasonality, and plant communication in sagebrush. J Plant Interact 6:85-88 
Strauss SY, Agrawal AA (1999) The ecology and evolution of plant tolerance to herbivory. Trends Ecol Evol 14:179-185 Strauss SY, Zangerl AR (2002) Plant-insect interactions in terrestrial ecosystems. In: Herrera CM, Pellmyr O (eds) Plant-animal interactions. Blackwell Sciences, Oxford

Strauss SY, Rudgers JA, Lau JA, Irwin RE (2002) Direct and ecological costs of resistance to herbivory. Trends Ecol Evol 17:278-285
Tucker C, Avila-Sakar G (2010) Ontogenetic changes in tolerance to herbivory in Arabidopsis. Oecologia 164:1005-1015

Wäckers FL, Bezemer TM (2003) Root herbivory induces an above-ground indirect defence. Ecol Lett 6:9-12

Walling LL (2000) The myriad plant responses to herbivores. J Plant Growth Regul 19:195-216 